\title{
Concrete columns confined with different composite materials
}

\author{
Jacopo Donnini ${ }^{1, *}$, Valeria Corinaldesi ${ }^{1}$ \\ ${ }^{1}$ SIMAU Department, Università Politecnica delle Marche, Ancona, Italy
}

\begin{abstract}
In the last decades, the need for upgrading, strengthening and retrofitting of existing concrete structures is rapidly growing. Composite materials showed to be an optimal solution to face this problem, combining high efficacy with low invasiveness. The use of Fiber Reinforced Polymers (FRP) to wrap concrete columns has been widely investigated and became a very successful method to improve their structural performances. However, it has been recognized that FRPs, due to the presence of an organic resin, have a few drawbacks, such as poor mechanical behavior at high temperatures, lack of vapor permeability and impossibility to be installed on wet surfaces. This experimental work aims to propose a comparison between three different innovative methods as possible strengthening solutions for existing concrete columns. The structural behavior of 20 reduced scale concrete columns, realized by using a low performance concrete, in order to reproduce the poor mechanical properties of existing structures, was investigated. Two unreinforced column were tested in compression as reference. Six of them where reinforced by applying an external layer of FRP, with different types of fabric reinforcement (made of carbon or PBO fibers). Six columns were reinforced by using the same fabrics coupled with an inorganic matrix (FRCM) instead of epoxy. Six other columns were reinforced by using a layer of High Performance Fiber Reinforced Concrete (HPFRC) of $3 \mathrm{~cm}$ thick. Experimental results have been analyzed and performance of the three reinforcement systems have been compared.
\end{abstract}

\section{Introduction}

The possibility of reinforcing concrete elements by externally applying fiber reinforced polymer (FRP) systems has become a well-established solution within the construction industry. The effectiveness of these systems has been validated by several experimental investigations [1-4].

FRPs combine several advantages over more traditional reinforcement systems, such as high strength to weight ratio, relative ease and speed of application, cost effectiveness. However, the presence of the organic resin (usually epoxy) involves some drawbacks and limitations, such as poor fire and high temperature resistance, inapplicability on wet surfaces, irreversibility, low compatibility with the substrate and low breathability. The attempt to overcome these limits has led to the development of new composite materials consisting of fibers in the form of fabric meshes or grids coupled with inorganic matrices, designed as Fiber Reinforced Cementitious Matrix (FRCM) systems. The inorganic matrix, that not necessarily is cement based but can also consists of lime-based or geopolymer mortars, ensures higher compatibility with the masonry or concrete substrate, guarantees higher performances when exposed to high temperatures or in case of fire, it can be applied on wet surfaces and is safer for operators [5-6]. FRCM systems proved to be very effective as external reinforcement for masonry or concrete elements, even though the adherence developed at the interface between fabric and mortar is not as high as in the case of organic based systems (FRPs).

The effectiveness of FRCM systems (also called Textile Reinforced Concrete, TRC) as external reinforcement of existing concrete elements has been investigated by several authors [7-9]. Bournas et al. carried out some tests on reinforced concrete columns strengthened both with TRM and FRP jackets [10]. Results showed that TRM jackets are slightly less effective in terms of increasing strength and deformation capacity by approximately $10 \%$. An experimental study on FRCM strengthening systems was carried out by Ombres, to analyze the performances of plain concrete elements wrapped with PBO fiber meshes embedded into an inorganic matrix [11]. The fibers reinforcement ratio, fibers orientation and compressive concrete strength were the parameters investigated. The PBOFRCM system showed to be effective in confining concrete by significantly increase both the peak strength and axial strain. The failure mode observed was due to loss of compatibility and separation at the fabric to matrix interface.

The use of High Performance Mortar (HPM) jackets is another of the emerging possibilities to reinforce existing concrete elements. The use of HPM results in many advantages if compared to normal reinforced concrete jackets: reduction in jacket size, ease of

* Corresponding author: j.donnini@univpm.it 
execution, reduction or elimination of need for additional steel reinforcement and cost effectiveness [12-14]. HPM are able to achieve compressive strength greater than 100 $\mathrm{MPa}$ and flexural strength higher than $30 \mathrm{MPa}$. Mechanical properties of HPM can be improved through the use of steel or glass fibers [15]. In addition, the use of Calcium Oxide showed to further improve the mortar mechanical properties [16].

\section{Experimental investigation}

In this study, 20 cylindrical concrete columns having a diameter of $140 \mathrm{~mm}$ and height of $460 \mathrm{~mm}$ have been realized and reinforced with FRP, FRCM or HPM and tested in compression. The three techniques have been compared in terms of effectiveness and invasiveness of the intervention.

\subsection{Material properties}

A concrete with poor mechanical properties (see Table 1) was used to cast the columns, in order to reproduce the real conditions that can be found in existing concrete structures that need to be reinforced. Two FRCM mortars with different strength classes were used, denoted as M15 and M45, while a two-component epoxy resin was used for FRP systems. Mechanical properties of the matrices were determined on specimens $40 \times 40 \times 160 \mathrm{~mm}$, after 28 days of curing at $\mathrm{RH}=50 \pm 5 \%$ and $\mathrm{T}=20 \pm 2{ }^{\circ} \mathrm{C}$, according to UNI EN 1015-11:2007. Results are reported in Table 1.

Table 1. Mechanical properties of the matrices

\begin{tabular}{|l|c|c|c|}
\hline Material & $\begin{array}{c}\text { Compressive } \\
\text { strength } \\
\text { (MPa) }\end{array}$ & $\begin{array}{c}\text { Flexural } \\
\text { strength } \\
\text { (MPa) }\end{array}$ & $\begin{array}{c}\text { Elastic } \\
\text { modulus } \\
\text { (GPa) }\end{array}$ \\
\hline Concrete & 14 & 1.3 & 11.4 \\
\hline Mortar M15 & 17 & 3.6 & 12.5 \\
\hline Mortar M45 & 50 & 6.2 & 34.5 \\
\hline HPM_FA_S & 128 & 34.1 & - \\
\hline HPM_FA_G & 91 & 13 & - \\
\hline $\begin{array}{l}\text { HPM_SF_S_ } \\
\text { E }\end{array}$ & 144 & 27.1 & - \\
\hline Epoxy resin & 59 & 48 & 1.87 \\
\hline
\end{tabular}

Three HPM with different compositions and mechanical properties were prepared, using a commercial Portland-limestone blended cement type CEM I 52.5 R, according to the European Standards EN$197 / 1$ and, as aggregate, a quartz sand with particle size up to $1.0 \mathrm{~mm}$. A water-reducing admixture constituted of a carboxylic acrylic ester polymer was used to maintain a low water to cement ratio. A low-calcium fly ash (ASTM C 618 Class F) produced by a thermal generating station was used. The Blaine fineness of fly ash is $480 \mathrm{~m}^{2} / \mathrm{kg}$ and its relative density (specific gravity) is 2.25 . Finally, short fibers made of brasscoated steel or glass, with nominal length of 13 and 12 $\mathrm{mm}$ respectively, were used as randomly dispersed reinforcement for the three HPM mixtures. The mixture proportions are reported in Table 2.

The use of different fabric reinforcement was investigated. In the case of FRCM, carbon or PBO fabrics were used. The PBO fabric is formed by yarns 10 $\mathrm{mm}$ and $20 \mathrm{~mm}$ spacing in the two orthogonal directions, nominal equivalent thickness of $0.046 \mathrm{~mm}$ in the longitudinal direction and $0.0224 \mathrm{~mm}$ in the transversal direction. The carbon fabric has nominal thickness of $0.048 \mathrm{~mm}$ in the two orthogonal directions and spacing between yarns of $20 \mathrm{~mm}$. Mechanical properties of the fabrics are reported in Table 3. The same fabrics have been impregnated and bonded to concrete with an epoxy resin (FRP) or with a cement based matrix (FRCM). In the case of FRP a unidirectional carbon sheet $\left(300 \mathrm{~g} / \mathrm{m}^{2}\right)$ was also tested and compared to the carbon and PBO fabrics.
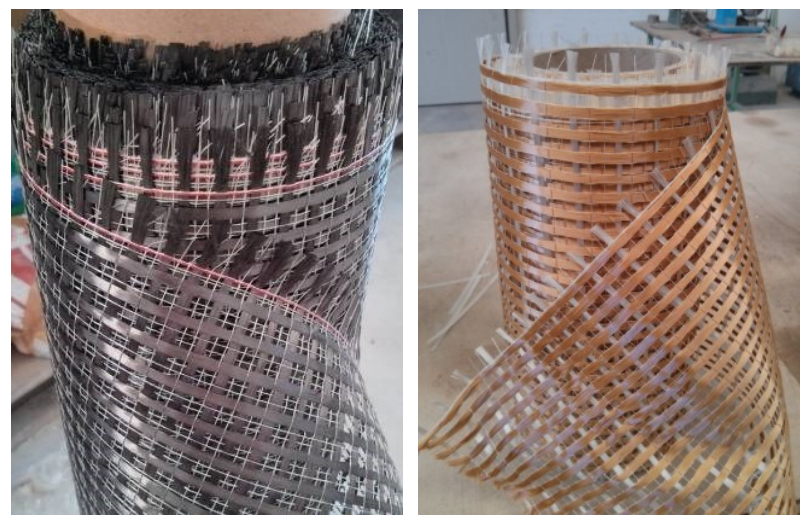

Fig. 1. Carbon and PBO fabrics

Table 2. High Performance Mortars mixtures $\left(\mathrm{kg} / \mathrm{m}^{3}\right)$

\begin{tabular}{|c|c|c|c|}
\hline & ${ }_{-\mathrm{S}}^{\mathrm{HPM} F A}$ & $\mathrm{HPM}_{-\mathrm{G}}^{\mathrm{H} F A}$ & $\underset{\mathrm{E}}{\mathrm{HPM}}$ \\
\hline CEM I 52.5 R & 960 & 960 & 960 \\
\hline Water & 240 & 240 & 240 \\
\hline Sand & 960 & 960 & 960 \\
\hline Fly ash & 250 & 250 & 250 \\
\hline Superplasticiz & 96 & 96 & 96 \\
\hline Steel fibers & 192 & - & 192 \\
\hline Glass fibers & - & 66 & - \\
\hline $\mathrm{CaO}$ & - & - & 35 \\
\hline SRA & - & - & 4 \\
\hline
\end{tabular}


Table 3. Physical, mechanical and geometrical characteristics of the fabrics

\begin{tabular}{|l|c|c|c|}
\hline Material & $\begin{array}{c}\text { Tensile } \\
\text { strength } \\
\text { fiber } \\
(\mathrm{MPa})\end{array}$ & $\begin{array}{c}\text { Elastic } \\
\text { modulus } \\
(\mathrm{GPa})\end{array}$ & $\begin{array}{c}\text { Ultimate } \\
\text { strain }\end{array}$ \\
\hline Carbon fabric (CF) & 4800 & 235 & 1.5 \\
\hline Carbon sheet (CS) & 4800 & 240 & 1.8 \\
\hline PBO fabric & 5800 & 270 & 2.5 \\
\hline
\end{tabular}

\section{Specimens preparation and test setup}

All specimens were manufactured by the same concrete batch, cast into a cylindrical plastic formwork, demoulded after 7 days and cured at laboratory conditions $\left(70 \% \mathrm{RH}, 20^{\circ} \mathrm{C}\right)$ for 28 days. All specimens were cleaned and the surface was smoothed with a sander before the application of the reinforcement.

FRCM systems were applied as indicated by the manufacturer, manually spreading a first layer of mortar with a thickness of $3 \mathrm{~mm}$ and applying the $\mathrm{PBO}$ or carbon fabric, slightly pressing it into the mortar. A fabric overlap of $150 \mathrm{~mm}$ was provided in each confined specimen. The second mortar layer was applied with the same thickness.

The application of FRP reinforcements was carried out by qualified personnel from the manufacturer. First, a primer and epoxy filler was applied to the concrete surface to eliminate surface defects and improve adhesion of the next resin layer. Then, carbon or PBO fabrics were applied by using a two component epoxy resin. A fabric overlap of $100 \mathrm{~mm}$ was provided in each confined specimen to assure the development of full composite strength.

HPM were cast within cylindrical plastic formwork, with an internal diameter equal to $200 \mathrm{~mm}$, so as to ensure a reinforcement thickness of $30 \mathrm{~mm}$. The high workability of the HPM mixtures allowed to easily cast them inside the formworks, without the need for vibration.

After strengthening, specimens were cured at laboratory conditions for another 28 days. Top and bottom surfaces of all columns were capped with sulphur to assure parallel surfaces and uniform load distribution.

All specimens were tested under uni-axial compression, using a $1500 \mathrm{kN}$ compression machine, through monotonically applied loading at a rate of 0.3 $\mathrm{mm} / \mathrm{min}$ (Figure 2). An exception was made for specimens reinforced with HPM, tested using a $5000 \mathrm{kN}$ compression machine. Applied loads were measured from a load cell while axial displacements were measured by using external linear variable differential transducers (LVDT) mounted on two opposite sides of the specimen. Axial strains were calculated from the LVDT measurements.

\section{Experimental results}

Results of all compression tests are summarized in Table 4, while stress-strain curves are reported in Figure
3. The maximum load $\left(F_{\max }\right)$, peak strength $\left(f_{c c}\right)$ and strain $\left(\varepsilon_{\mathrm{cc}}\right)$ of reinforced specimens have been reported.

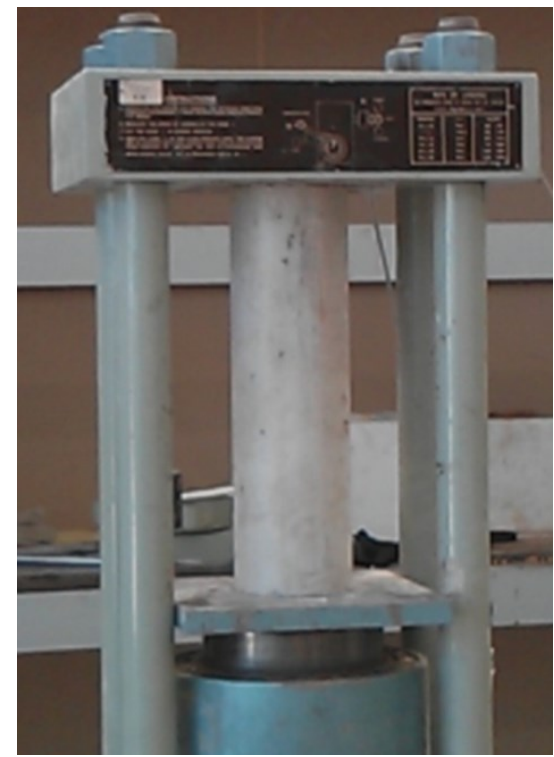

Fig. 2. Compression test setup

The average peak strength of the unconfined specimen was equal to $11.41 \mathrm{MPa}$ while the ultimate strain was $0.359 \%$. In Table 4 the values of the ratios between the peak strength of the confined specimens, $f_{c c}$ and that of the reference specimen $f_{c 0}$ and between the ultimate axial strain of the confined $\left(\varepsilon_{\mathrm{cc}}\right)$ and unconfined $\left(\varepsilon_{\mathrm{c} 0}\right)$ specimens are also reported. Results of tests are presented and discussed in terms of stress-strain response, ductility and failure modes.

Table 4. Results of compression tests on concrete specimens

\begin{tabular}{lccccc}
\hline Specimen & $\begin{array}{c}\mathrm{F}_{\max } \\
(\mathrm{kN})\end{array}$ & $\begin{array}{c}f_{c c} \\
(\mathrm{MPa})\end{array}$ & $\begin{array}{c}\varepsilon_{\mathrm{cc}} \\
(\%)\end{array}$ & $f_{c c} / f_{c 0}$ & $\varepsilon_{\mathrm{cc}} / \varepsilon_{\mathrm{c} 0}$ \\
\hline Ref_1 & 170 & - & - & - & - \\
Ref_2 & 181 & - & - & - & - \\
\hline E_CS_1 & 497 & 32.31 & 1.778 & 2.92 & 5.13 \\
E_CS_2 & 477 & 31.01 & 1.742 & 2.72 & 4.85 \\
E_PBO_1 & 330 & 21.45 & 1.271 & 1.94 & 3.67 \\
E_PBO_2 & 321 & 20.87 & 1.259 & 1.83 & 3.51 \\
E_CF_1 & 305 & 19.83 & 1.297 & 1.79 & 3.74 \\
E_CF_2 & 297 & 19.31 & 1.107 & 1.69 & 3.08 \\
\hline M15_CF_1 & 205 & 13.32 & 0.566 & 1.20 & 1.63 \\
M15_CF_2 & 215 & 13.98 & 0.550 & 1.23 & 1.53 \\
M45_PBO_1 & 279 & 18.14 & 1.117 & 1.64 & 3.23 \\
M45_PBO_2 & 258 & 16.76 & 1.062 & 1.47 & 2.96 \\
M45_CF_1 & 213 & 13.85 & 0.488 & 1.25 & 1.41 \\
M45_CF_2 & 207 & 13.46 & 0.481 & 1.18 & 1.34 \\
\hline HPM_FA_G_1 & 1200 & 38.23 & 0.451 & 3.45 & 1.30 \\
HPM_FA_G_2 & 1144 & 36.43 & 0.417 & 3.20 & 1.16 \\
HPM_FA_S_1 & 1430 & 45.54 & 0.584 & 4.11 & 1.69 \\
HPM_FA_S_2 & 1356 & 43.18 & 0.504 & 3.79 & 1.40 \\
HPM_SF_S_E_1 & 1640 & 52.23 & 0.777 & 4.71 & 2.25 \\
HPM_SF_S_E_2 & 1601 & 50.99 & 0.730 & 4.47 & 2.03 \\
\hline & & & & &
\end{tabular}




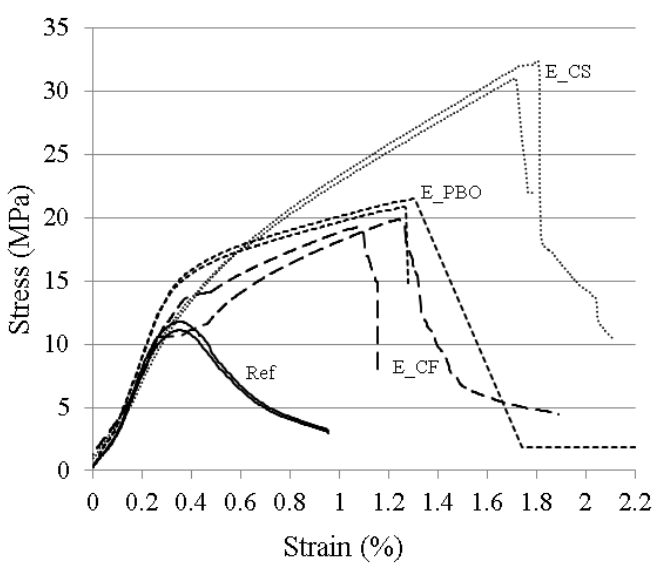

FRP

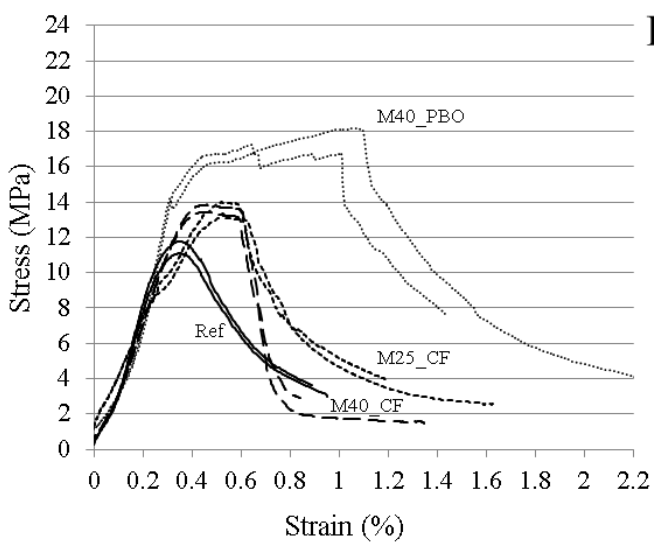

FRCM

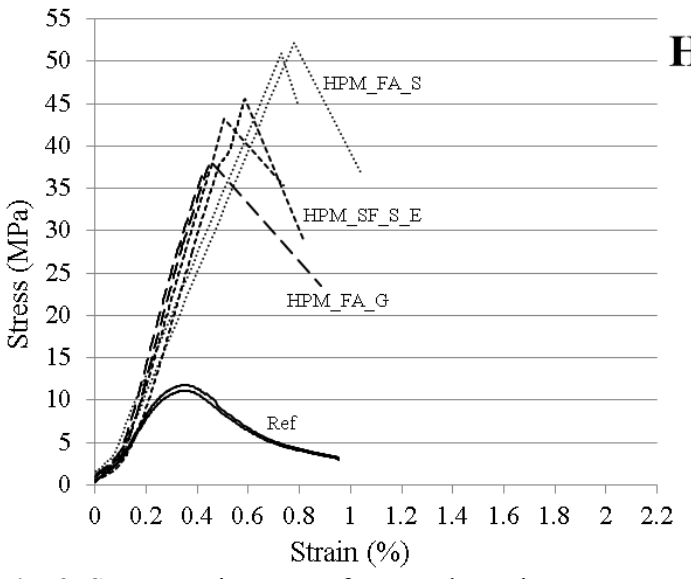

Fig. 3. Stress-strain curves for tested specimens

Test results showed that all the composite materials used to wrap the concrete specimens were able to significantly increase their compressive strength. However, in the case of FRP and FRCM reinforcement, the stress strain curve is characterized by three different stages. In the first part the curve is almost linear and most of the load is carried out by the concrete cylinder. The slope of the stress strain curve in this stage is similar to that of the reference specimen. Once the concrete core starts to crack and damage the external reinforcement is activated. In this second stage the slope of the stress strain curve varies depending on the type of reinforcement used. The carbon sheet (E_CS, $300 \mathrm{~g} / \mathrm{m}^{2}$ ) provided the best performing solution by increasing the compressive strength of about 2.7 times. The columns reinforced with PBO (E_PBO, $146 \mathrm{~g} / \mathrm{m}^{2}$ ) and carbon (E_CF, $172 \mathrm{~g} / \mathrm{m}^{2}$ ) fabrics increased the ultimate compressive strength of 1.8 and 1.7 times respectively. The failure mode of tested specimens was due to fibers failure at the center of the column.

Columns reinforced with FRCM systems showed a different behavior. In this case the stress strain curve can be divided into 4 stages. After the failure of the inner concrete the specimen maintains a high stiffness, due to the presence of the FRCM inorganic matrix, and the slope of the curve is higher if compared to FRP wrapped specimens. At the end of this stage, the inorganic matrix starts to crack and the fabric reinforcement is activated. The third phase is characterized by the slippage of the fabric within the inorganic matrix. This phenomenon has been clearly highlighted in other studies concerning the mechanical characterization of FRCM systems [17-19]. The slope of the curve in this stage depends on the friction developed at the interface between fabric and inorganic matrix. FRCM systems increased the compressive strength of the concrete columns of 1.2 up to 1.6 times the initial strength. Best performances were obtained by using a unidirectional PBO fabric coupled with an inorganic matrix specifically designed for concrete substrates. This system was also able to significantly increase the ductility of the concrete element. Ultimate strain was 3 times higher than that of the unreinforced specimen. Failure mode was always by fibers slippage and breakage (due to the friction with the inorganic matrix), after the formation of several longitudinal cracks on the mortar surface.

Columns reinforced with HPM showed a different behavior. In this case the load is carried out only by the external mortar, which is more resistant and stiffer than the internal concrete. The stress strain curve is almost linear up to reach the failure of the external HPM. The system proved to be very effective in increasing the ultimate compressive strength, even if ductility of the concrete element, if compared with columns reinforced with FRP or FRCM systems, was reduced. The columns reinforced with HPM_FA_G failed due to the complete breakage of the external mortar, which detached from the internal concrete element. Columns reinforced with HPM and steel fibers (HPM_SF_S_E, HPM_FA_S) showed a higher peak load and a different failure mode. In this case the HPM cracked but remained attached to the internal concrete column.

\section{Conclusions}

The use of three different techniques to reinforce concrete columns was investigated. All of them proved be effective, even if the mechanical behavior of the reinforced column, final performances and failure modes were different. 

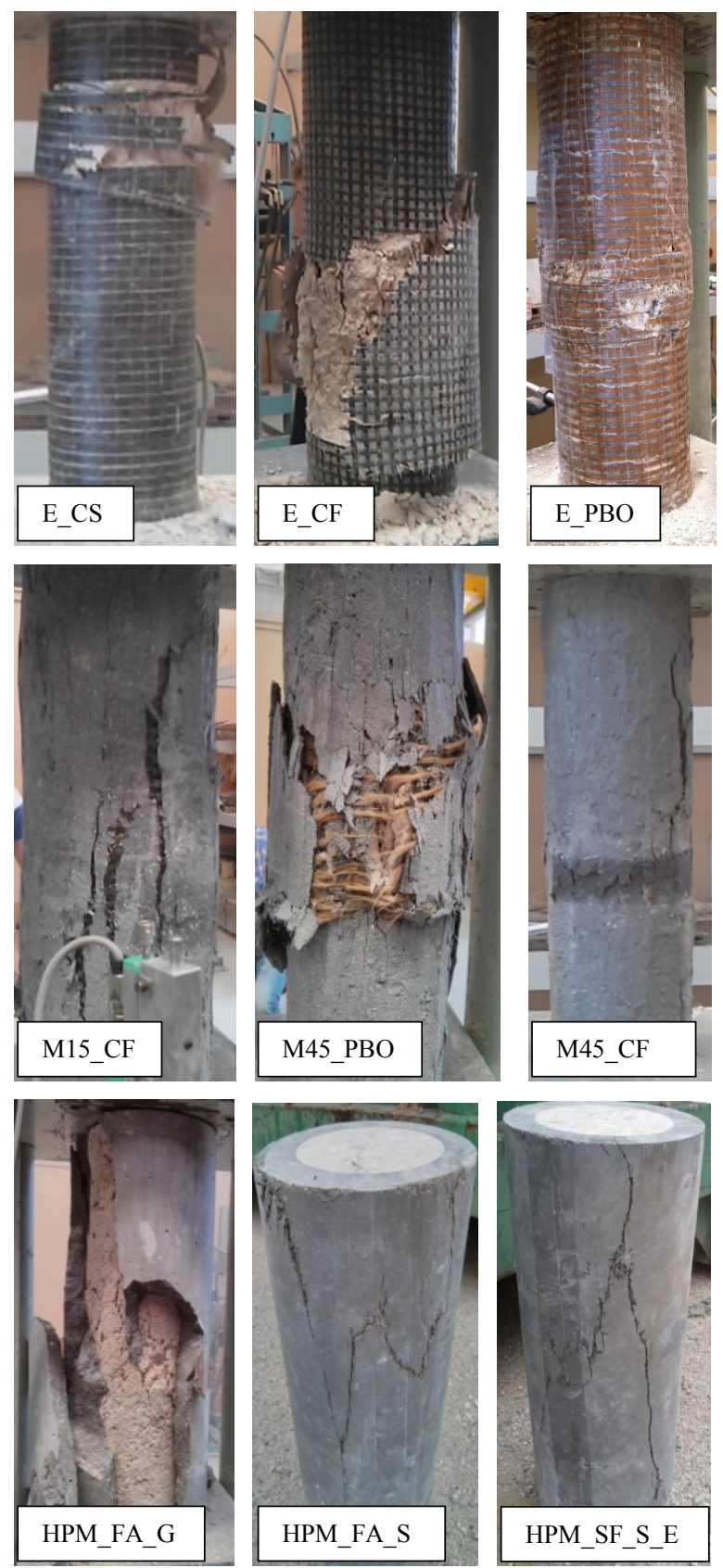

Fig. 4. Specimens at failure

FRCM proved to be less effective than FRP, when the same fabric reinforcement was used. The peak strength of the column reinforced with carbon fabric coupled with an inorganic matrix (FRCM) was about $28 \%$ lower than that of the same fabric coupled with an epoxy resin (FRP). This phenomenon is due to the different ability to impregnate the carbon or PBO fabrics by the organic (FRP) and inorganic (FRCM) matrix. This fact is also underlined by the different failure modes observed: FRP always failed due to fabric rupture, FRCM failed due to slippage of the fabric within the inorganic matrix (and subsequent breakage).

HPM showed to significantly increase the compressive strength of the concrete columns. This is due to the high compressive strength of these mortars, if compared to the concrete columns. The load is carried out only by the external HPM jacket and no damage observed in the internal concrete. However, ductility of concrete columns reinforced with this system is reduced, if compared to FRP or FRCM systems.

\section{References}

1. A. Ilki, O. Peker, E. Karamuk, C. Demir, N. Kumbasar. Journ Mat Civ Eng 20, 169-188 (2008).

2. J.F. Berthet, E. Ferrier, P. Hamelin. Constr Build Mater 19, 223-232 (2005)

3. A. Nanni, N.M. Bradford. Constr Build Mater 9, 115-124 (1995)

4. R. Realfonzo, A. Napoli. Comp Part B: Eng 42, 736-755 (2011)

5. V. Corinaldesi, J. Donnini, G. Mazzoni. Key Eng Mat 624, 189-196 (2015)

6. J. Donnini, F. De Caso y Basalo, V. Corinaldesi, G. Lancioni, A. Nanni. Comp Part B: Eng 108, 108121 (2017)

7. T. Trapko. Constr Build Mater 73, 332-338 (2014)

8. P. Colajanni. F. De Domenico, A. Recupero, N. Spinella. Constr Build Mater 52, 375-384 (2014)

9. C.G. Papanicolau, T.C. Triantafillou, K. Karlos, M. Papathanasiou. Mat and Struct 40, 1081-1097 (2007)

10. D.A. Bournas, P. Lontou, C.G. Papanicolau, T.C. Triantafillou. ACI Struct J 104, 740-748 (2007)

11. L. Ombres. Eng Fract Mech 81, 94-109 (2012).

12. C. Beschi, A. Meda. P. Riva. Journ Earth Eng. 15, 989-1014 (2011)

13. B. Rabehi, Y. Ghernouti, A. Li, K. Boumchedda. $J$ Adhes Sci and Techn 28, 2327-2346 (2014)

14. A. Marini, A. Meda. Eng Struct 31, 3059-3064 (2009)

15. V. Corinaldesi, J. Donnini, A. Nardinocchi. J Build Eng 4, 14-20 (2015)

16. V. Corinaldesi, A. Nardinocchi, J. Donnini. Constr Build Mater 91, 171-179 (2015)

17. J. Donnini, V. Corinaldesi. Constr Build Mater 145, 565-575 (2017)

18. T. D'Antino, C. Carloni, L.H. Sneed, C. Pellegrino. Eng Fract Mech 117, 94-111 (2014)

19. J. Donnini, G. Lancioni, V. Corinaldesi. Comp Part B: Eng 140, 5767 (2018) 